\title{
What Are the Factors Underlying the Differences between Young Saudi Women in Traditional Families That Choose to Conform to the Society Norms, and Young Saudi Women Who Do Not Conform?
}

\author{
Mai Al-Subaie
}

\begin{abstract}
This research suggests that women in traditional families of Saudi Arabia are divided into two groups, the one who conforms to the society and the new type of women that has been emerged due to the changing and development of the culture, who do not want to conform to the rules. The factors underlying the differences were explored by using a test and an interview. And that concluded some of the main factors that were a real affect of why some women still want to follow the society and traditional rules, and other want to break free.
\end{abstract}

Keywords-Conformity, Non-Conformity, Saudi Arabia, Women.

\section{INTRODUCTION}

$\mathrm{Y}$ OUNG women in the Saudi culture will grow up to find their path is set and ready for them, with the social expectation to be the follower and to obey what society wants her to be. Leading all women to be the same, and leaving them without any choices signifies that women in the Saudi culture conform to their society norms without questing them. However, in the past few years the circumstances have changed, leading to a paradigm shift, women in Saudi Arabia started to speak yet not loudly leading to add some minor changes to their life. "The consequential awareness in women at the advent of emerging feminist consciousness has heightened their questioning openly regarding their status in their family and society and especially doubts regarding their roles assigned to them by the patriarchal society such as a dependent daughter, wife and mother and as a member of the society" [1]. Subsequently, this research pursuing the factors in which women in the traditional family that conform to their society and why do they still accept it. And the other new type of women that have been emerged, due to the changes that occurred in the Saudi culture, who do not choose to accept the traditional way as being a Saudi female. The first category comes under conformity, and conformity indicates the social pressure, which can influence the behavior of the individual, which leads the person not to become different than others around him/her. Act according to the traditions and culture rules without thinking of changing them is the second type of women who comes under the non-conformity. The non-

Mai Al-Subaie is with the Psychology Department, Effat University, Jeddah, Saudi Arabia (e-mail: Mai.m.alsubaie@gmail.com). conformity is the refusal to accept the roles of the social norm that society has put for the individual to follow, and nonconformity has many motivations to lead the person to this decision. Under the non-conformity there is something called the need for uniqueness feeling, which can lead the person to feel different then other around him. "Conversely, being too similar to others has been described as evoking aversive feelings and motivating compensatory action. Under certain conditions, it may not subjectively appear gratifying to think or say what most others do. We presently propose that one such condition is met when recipients of influence experience a high need for uniqueness (NFU).” [2]. As a consequence it may be one of the reasons that lead Saudi women to strive for that feeling, which also can be considered as freedom, by not conforming. The NFU proposes that women who do conform to their society lack this feeling. A scale was developed in order to measure the NFU. This scale measures individual differences in the need for uniqueness, which helps predict people's willingness to resist conformity pressures. High scores on the scale indicate a greater need for uniqueness and a lesser likelihood to conform to the group. Low scores on the scale represent a lesser need to be unique and a greater tendency to conform to the group. "[6] Began by generating a pool of 300 potential scale items and using judges rating of each items face validity to narrow the pool to 117 items. Then they examined the correlation of these 117 items with individual difference measures of autonomy and succorance. 32 items correlated positively with autonomy and negatively with succorance are selected for inclusion in their final scale" [3]. Subsequently, this research there will be four case studies about the two types of Saudi women. Data will be collected, by using interviews, and (NFU) Need for uniqueness test scale in order to answer the question on what are the factors underlying the differences between young Saudi women that choose to conform to the society norms and others who choose not to conform to them?

\section{A. Conformity}

In the context of not conforming to the society norms, Saudi Arabia may be having an emerging feminist consciousness or a silent feminist movement like other countries before. "In the recent decades, we witness certain changes in the interpersonal relationship between men and women. There seems to be certain reluctance on women's part in undertaking the 
varied roles and in conforming to such roles within the tight cultural, traditional, societal and psychological established norms. Marriages are postponed or the newlyweds are divorced no sooner than they get married, and motherhood is considered burdensome and hence pregnancy is postponed or avoided. Women seem to be constantly in search of an extra space to fit in individually and independently" [3]. These changes are appears to be found here within the new generation of young Saudi women, especially the one who chose not to conform to the rules. Additionally it can be seen the women nowadays postponed the marriage idea for the sake of education, which is conceder to be a bold yet new way to act as their own individuals. The important key to understand the factors of why women are split into two groups is by looking to the past, which is how the Saudi cultures is structured, and how it's been evolved in the past few years, and the influences that has affected by it. According to [4] "It has been recognized that tradition and modernity need not be opposing or dichotomous. It is not necessary to resist modernity to remain rooted in tradition. In fact individuals and cultures derive a lot from their past, mingle it with the experiences of the present and make necessary modifications for a better future. Thus, the past and the present in a way overlap and help strengthen each other.” In a book titled by "A Kingdom's Future: Saudi Arabia through the Eyes of Its Twenty Something's" which focuses on the young Saudi generation, tries to recognize the old factors that helped in shaping the future generation like talking about the social status of people in Saudi Arabia, also their religious orientation and believe, saying, "Saudi Arabia is the world's largest oil producer, the spiritual home- land of Sunni Islam and a heavyweight in regional diplomacy and trade. It also is the economic and military powerhouse of the Gulf Cooperation Council, whose six member nations are ruled by hereditary monarchies and royal families. Socially and politically conservative, the GCC bloc is also youthful, with those under 25 comprising 54 percent of the region's population." Moreover "it is quickly evident to visitors that the kingdom is a youth- full place. Infants, toddlers and teens abound in shopping malls, parks and restaurants. Sixty-four percent of its 19.4 million citizens are under age 30. Those aged 12 to 16 are 12 percent of the population; making them the Kingdom's largest-ever “youth bulge." [5]. It's unambiguous that all of that and much more like the media role can be the reason for such a change in the Saudi culture and their youth specially young women, however these causes are not enough to underlying the main factors to recognize why some women do conform and other do not.

\section{METHODS}

This exploratory qualitative study involved young Saudi women, and the type of the data collection that will be introduced in this research will be by using interviews and test. In addition to the type of the questions that will be asked in the interview will have a structured questions form. And the participant will have to take "Need for uniqueness" measurement scale in order to help in recognizing the factors.
The participants were Saudi young females, from traditional families, between the ages of 20 to 26. Divided into four women, two comes under the title of conformity, and the other two comes under the title of who don't conform, to explore their perceptions of what they concede the factors of both conforming and non-conforming in Saudi society. There will be no specific way of recruitment. However the participants will be from native Saudi families

\section{RESUlTS}

\section{A. Abbreviations and Acronyms (NFU) Need for Uniqueness Scale}

Four women participated in taking the (NFU) scale: the two conformist women scored low in the scale that is the need for uniqueness. While the two other women who are nonconformist scored high in the measurement scale.

TABLE I

NEED FOR UNIQUENESS

\begin{tabular}{lll}
\hline \hline \multicolumn{1}{c}{ Participants } & Conformist & Non-Conformist \\
first participant & 89 & \\
second participant & 93 & \\
third participant & & 99 \\
forth participant & & 106 \\
\hline \hline
\end{tabular}

The score range is from 98 to 108. If the participants scored lower than 98 , they may be more likely to conform compared to other people. However if they scored higher than 108, the participants are less likely to conform compared to others. These results showed that women who are not conformist tend to have also wanted the feeling for being unique and different. On the other hand the women who are conformist they don't have that much of a need for being unique.

\section{B. Interview}

The main important results that have been concluded from the interview helped to underline some of the main factors on Saudi women, who are conformist and non-conformist. Some of the factors come under the affect of media, parents and family, and religions orientation. The media was a great distress on both the conformist and non-conformist women. Accordingly, In the case of the conformist women their perception of media was different, it is believed that media is important as it's a part of their life. However, they don't let it control them and their way of thinking, even if something has influenced them, they will look first at their society rules then decide whether they can accept it or reject it. According to an interviewer who is conformist said: "Traditions are conceders important when perceiving the media" which means that they think twice before accepting it's influence. On the other hand, non-conformist women showed an alternative view by considering media as an important factor to their development. According to non-conformist women said "I see media as an entertainment tool, educational, and I see it as the biggest impact on our life". The other important factor was the enormous influence that family especially parents has on their daughters. First key to understand the both conformist and 
non-conformist is to look at their mothers, the results showed that both non-conformist women had an educated mother who encouraged them to study and think of their future from a practical point of view. According to one of the interviewers "My mother always reminded me that happiness of being independent and educated women is more important than the happiness of getting married". Conversely, the mothers of the two conformist women did not continue their education, they stopped at one point for the purpose of getting married, and that exactly what they want and expect from their daughters, which is to follow their path. Along with the great power that mothers have over the four women, the Extended family is another important factor. However, the results are different than the mothers' case. Both women who are non-conformist came from an authoritarian traditional family, and instead of accepting the family way of life they reject it. And the more the family was following the unforgiving rules; the women become more and more non-conformist which can lead them to break all the rules. "I don't want to socialize with my extended family, because they are so judgmental and they are so traditional. They always limit my opportunity to develop, and they always refer this to the traditions. For example like studying abroad, or getting married to someone I wish to be with" The conformist women however, they come from the same traditional families background, in spite of this the reason that they did not act like the non-conformist women may be because the mothers power of convincing them that the rules should be accepted and followed. One of the conformist interviewers answered the questions (Did your father always repeatedly remind you about the rules and the consequences of your actions?) her answer was "No, but my mother did that, by always reminding me to be careful and don't do any mistakes". The final factor is religion orientation, which indicates that the less religious the women are the more they have non-conforming ideas. Both women who are nonconformist they answered the question of (How do you categorize yourself on how religious are you) by saying they have a liberal way of thinking, and that means Muslims who have produced a considerable body of liberal though on the reinterpretation and reform of Islamic understanding and practice. Alternatively, conformist women they have more religious orientation, by seeing their religion as their life as a whole not like the liberal non-conformists who sees their religion as part of their life only.

\section{DISCUSSION}

The study used qualitative methods to explore the factors underlying the differences of conformity and non-conformity. The need for uniqueness scale along with the interview showed some important factors that lead young Saudi women either to conform or not to conform to their society and life around them. The first factor support the idea that women who are not conformist they do need to feel different and unique, that way they tend to have different way of thinking regarding their life and future, like creating their own rules and not following the traditional life that they see. Conversely, the findings in the (NFU) scale in addition to the interview showed interestingly some related thoughts between the conformist and non-conformist women that may suggest some limitation to the research which believes it has to do with another important factor that should be added in order to distinguish the differences between who conform and who do not conform. Therefore, this factor is personality. The differentiation between the two conformist women and the other two non-conformist women regarding personality was obvious. The non-conformist showed in the interview a strong personality that can be described as similar to a leadership personality trait, on the other hand the conformist women showed the complete contrary to that, by having a follower personality type, which indicates that personality might be another important factor.

\section{V.CONCLUSION}

The set roles on how to be a women and which path they should take was a normal thing for a young women in the Saudi culture. And the consequences will create a group of women who are similar in their way of thinking and in behavior, which indicates that conformity of women in the Saudi culture come doubtlessly. Conversely a paradigm shifts come into existence in women of Saudi Arabia, who disapprove on the traditional way of living and do not conform to their society. Women now a day's in the Saudi culture are divided into two categories. Woman in the traditional family who conform to their society, and the other new type of women that have been emerged, due to the culture changes, who do not choose to accept the traditional way as being a Saudi female. Therefore, the factors that underlie the differences between the two types of women are enthralling as well as important to study the effect and influences that happened to the new Saudi culture.

\section{ACKNOWLEDGMENT}

The author would like to express deepest appreciation to all those who provided with the possibility to complete this report. Many thanks go to Dr. Jannat Alabbasi whose with her comment and advices led to coordinate the project. Furthermore special thanks go to Noor Al-Enezi, Sara AlGhamdi, Samaa Al-Safwani, and Rakan Aqeel who helped to assemble the parts and gave suggestion about research. Last but not least, a special gratitude the author gives to the head of the project Dr. Annechien Helsdingen who has invested her full effort in guiding, and her contribution in stimulating suggestions and encouragement helped in achieving the goal.

\section{REFERENCES}

[1] Naarajan, D. N. (2010). Between Conformity and Non-Conformity: A Comparative Study of the Feminist Critique of the Patriarchal Roles of Women in Doris Lessing and Rajam Krishnan. In D. N. Naarajan. Pondicherry University.

[2] Erb, H. P., \& Imhoff, R. (2008, December 19). What Motivates Nonconformity? Uniqueness Seeking Blocks Majority Influence. 35.

[3] Cassell, E. J. (n.d.)

[4] Sahi, H. K. (2009). Negotiating with the Past and Contemporary Life of Indian Woman: A Study of the Works of ShashiDeshpande and Chitra Banerjee Divakaruni. 
[5] Murphy, C. A Kingdom's Future: Saudi Arabia through the Eyes of Its Twenty Somethings. Washington: Woodrowwilson International Center for Scholars.

[6] Snyder, C. R.; Fromkin, Howard L. 